\title{
Methodological Challenges in Protein Microarray and Immunohistochemistry for the Discovery of Novel Autoantibodies in Paediatric Acute Disseminated Encephalomyelitis
}

\author{
Patrick Peschl ${ }^{1,+}{ }^{,}$, Melanie Ramberger ${ }^{1,+}$, Romana Höftberger ${ }^{2}$, Karin Jöhrer ${ }^{3}$, \\ Matthias Baumann ${ }^{4}$, Kevin Rostásy ${ }^{5}$ and Markus Reindl ${ }^{1, *}$ \\ 1 Clinical Department of Neurology, Medical University of Innsbruck, Innsbruck A-6020, Austria; \\ patrick.peschl@i-med.ac.at (P.P.); ramberger.melanie@gmail.com (M.R.) \\ 2 Institute of Neurology, Medical University of Vienna, Vienna A-1090, Austria; \\ romana.hoeftberger@meduniwien.ac.at \\ 3 Tyrolean Cancer Research Institute, Innsbruck A-6020, Austria; karin.joehrer@tkfi.at \\ 4 Division of Paediatric Neurology, Department of Paediatrics I, Medical University of Innsbruck, \\ Innsbruck A-6020, Austria; matthias.baumann@tirol-kliniken.at \\ 5 Department of Paediatric Neurology, Witten/Herdecke University, Children's Hospital Datteln, \\ Datteln D-45711, Germany; k.rostasy@kinderklinik-datteln.de \\ * Correspondence: markus.reindl@i-med.ac.at; Tel.: +43-512-504-24363 \\ $\dagger$ These authors contributed equally to this work. \\ Academic Editor: William Chi-shing Cho \\ Received: 22 February 2017; Accepted: 17 March 2017; Published: 22 March 2017
}

\begin{abstract}
Acute disseminated encephalomyelitis (ADEM) is a rare autoimmune-mediated demyelinating disease affecting mainly children and young adults. Differentiation to multiple sclerosis is not always possible, due to overlapping clinical symptoms and recurrent and multiphasic forms. Until now, immunoglobulins reactive to myelin oligodendrocyte glycoprotein (MOG antibodies) have been found in a subset of patients with ADEM. However, there are still patients lacking autoantibodies, necessitating the identification of new autoantibodies as biomarkers in those patients. Therefore, we aimed to identify novel autoantibody targets in ADEM patients. Sixteen ADEM patients (11 seronegative, 5 seropositive for MOG antibodies) were analysed for potential new biomarkers, using a protein microarray and immunohistochemistry on rat brain tissue to identify antibodies against intracellular and surface neuronal and glial antigens. Nine candidate antigens were identified in the protein microarray analysis in at least two patients per group. Immunohistochemistry on rat brain tissue did not reveal new target antigens. Although no new autoantibody targets could be found here, future studies should aim to identify new biomarkers for therapeutic and prognostic purposes. The microarray analysis and immunohistochemistry methods used here have several limitations, which should be considered in future searches for biomarkers.
\end{abstract}

Keywords: acute disseminated encephalomyelitis; paediatric; autoantibody; autoantigen; protein microarray; immunohistochemistry

\section{Introduction}

Acute disseminated encephalomyelitis (ADEM) is an autoimmune disorder of the central nervous system (CNS) mainly affecting children and young adults. According to the International Paediatric Multiple Sclerosis Study Group (IPMSSG), diagnosis of the disease requires a polysymptomatic clinical presentation including focal neurological and encephalopathic symptoms, such as confusion, excessive 
irritability, lethargy, or coma [1]. The disease course is mainly monophasic with partial or complete recovery, but also multiphasic forms of ADEM have been observed with a recurrence of the initial symptoms or more distinct ADEM episodes appearing at least three months after the first event, making the differentiation to multiple sclerosis (MS) not always simple [2]. Therefore, the identification of disease specific biomarkers is a very important research aim.

One potential biomarker is an autoantibody against myelin oligodendrocyte glycoprotein (MOG), which is located on the outermost surface of myelin sheaths and oligodendrocytes. Several studies found a higher frequency of serum anti-MOG IgG antibodies (MOG antibodies) in paediatric patients with ADEM and other acquired demyelinating diseases, and a significant titre decrease within a period of 12 months in ADEM cases [3-11]. Baumann and colleagues found that $58 \%$ of investigated ADEM patients were positive for MOG antibodies at disease onset, with a significantly better recovery compared to seronegative patients [12]. However, a considerable group of ADEM patients are seronegative for MOG antibodies, usually also responding to anti-inflammatory treatment regimens or plasmapheresis, indicating the role of other yet unknown autoantibodies in the pathogenesis of the disease.

The aim of this study was therefore to search for novel autoantibodies in MOG antibody seronegative ADEM. For this purpose we analysed sera from ADEM patients by a protein microarray technique, which allows us to investigate 9375 potential antigens. In addition, we used immunohistochemistry (IHC) based on frozen rat brain sections to include a broad range of neuronal and glial surface and intracellular antigens.

\section{Results}

\subsection{Protein Microarray Did Not Discriminate between Paediatric ADEM Patients with and without MOG Antibodies}

As a first step, we investigated autoantibody profiles in paediatric ADEM patients by applying sera from five patients with serum MOG antibodies and 11 without serum MOG antibodies to a protein ProtoArray ${ }^{\circledR}$ (Invitrogen, Carlsbad, CA, USA) containing 9375 potential human autoantigens. Figure S1 shows an example of a protein ProtoArray ${ }^{\circledR}$ scan. The cut-off z-score was defined as $\geq 2.33$, corresponding to the top $1 \%$ quantile of all signals. A total of 228 proteins were identified as targets across all serum samples in at least one patient (Figure 1 and Table S1). Among these, 79 proteins were increased in all 16 samples. However, these proteins included mainly sequences of the immunoglobulin (Ig) family, which can be attributed to unspecific binding. All details to antigen-antibody reactivity are shown in Table S1. In the MOG antibody negative group, nine specific candidate proteins emerged having z-scores above the cut-off $(\geq 2.33)$ in at least two patients per group (Table 1$)$. The potassium channel KCNAB1 was included as a candidate antigen since two samples showed reactivity above the cut-off to variant 1 (v1) and v3 of KCNAB1, respectively. Although all mean z-scores of those nine proteins were higher in the MOG antibody seronegative patient group, none of them were significantly different between the two patient groups (Figure 2). Besides KCNAB1, we found an additional reactivity of $\geq 2.33$ to voltage-gated potassium channel subunit beta-2, transcript variant 1 (KCNAB2 v1), potassium channel tetramerisation domain containing 18 (KCTD18), and potassium channel tetramerisation domain containing 6 (KCTD6). Each one of these proteins was increased in at least one patient of the MOG antibody negative patient group. 


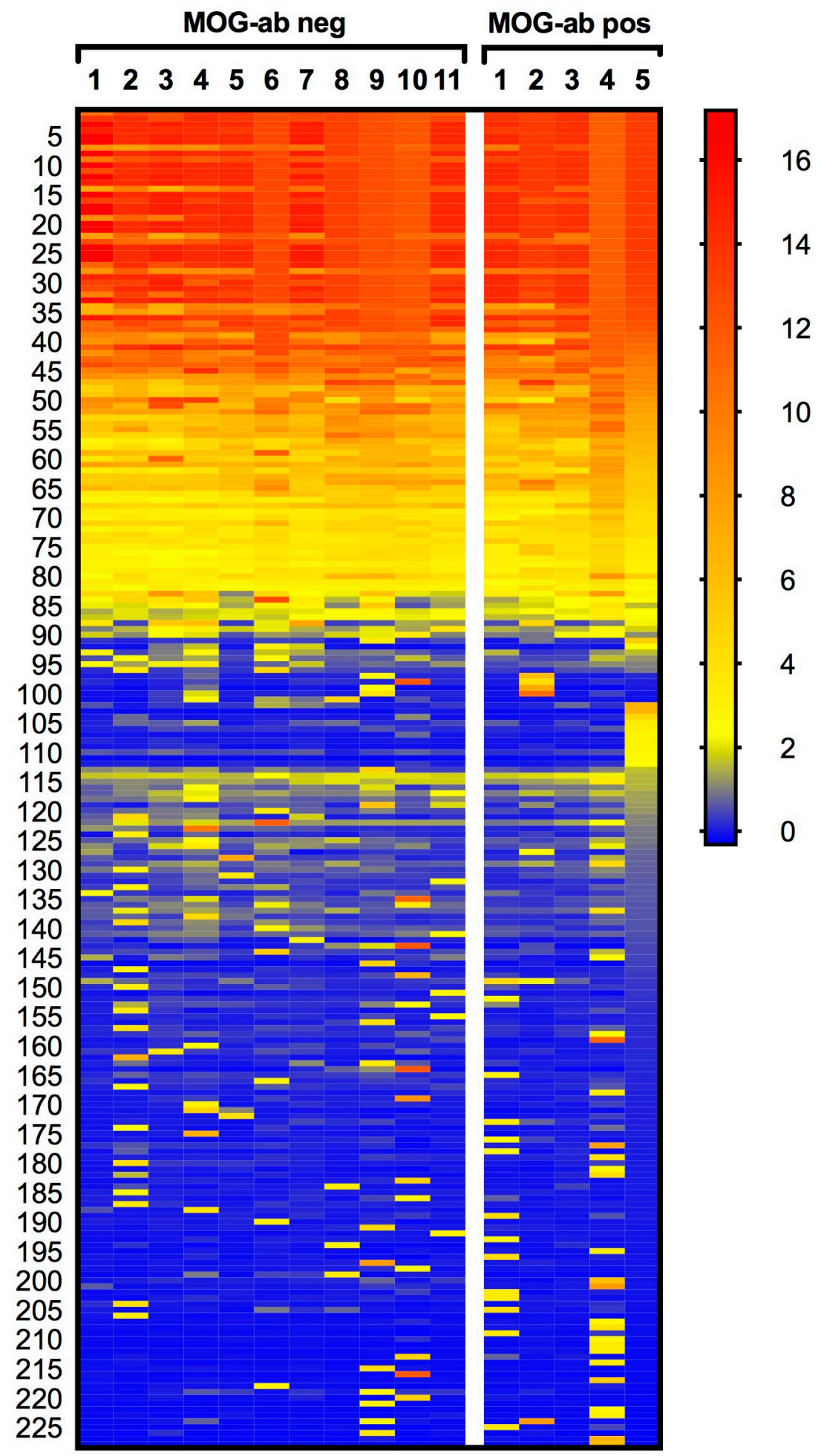

Figure 1. Heatmap of 228 proteins (see Table S1) with significant hits (z-score $\geq 2.33$ ) in at least one serum sample. Columns are individual serum samples from myelin oligodendrocyte glycoprotein antibody (MOG-ab) negative (neg, $n=11$ ) and positive (pos, $n=5$ ) acute disseminated encephalomyelitis (ADEM) patients; rows are proteins with a z-score $\geq 2.33$. Values range from blue $(-0.32)$ to yellow (2.33) to red (17), with a legend on the right side. 


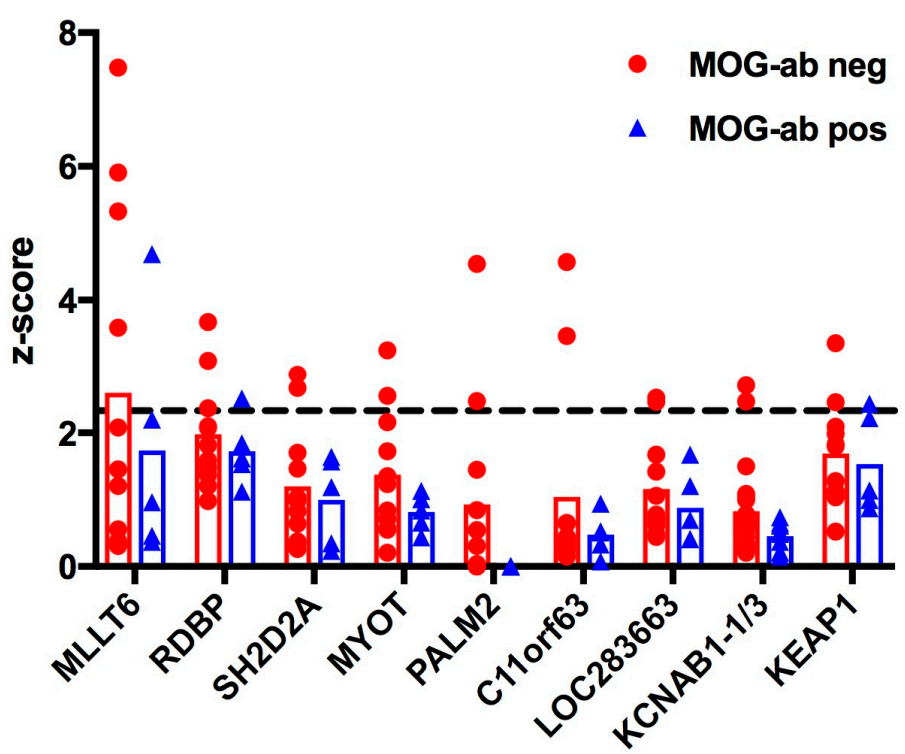

Figure 2. MOG antibody seropositivity does not significantly influence z-scores in paediatric patients with ADEM. Z-scores of candidate proteins (Y-axis) that exceeded the cut-off (2.33) in at least two patients per group are shown (for more details see Table 1). Means are indicated by the bars. The cut-off is shown as a dashed horizontal line. No significant differences were observed (matched two-way ANOVA). MLLT6: Myeloid/lymphoid or mixed-lineage leukaemia, translocated to, 6; RDBP: Negative elongation factor E (NELF-E); MYOT: Myotilin; PALM2: Paralemmin-2; C11orf63: Chromosome 11 open reading frame 63; LOC283663: hypothetical protein LOC283663; KCNAB1-1/3: Voltage-gated potassium channel subunit beta-1, variants 1 and 3; KEAP1: Kelch-like ECH-associated protein 1.

Table 1. Protein sequences with z-scores $\geq 2.33$ in at least two patients within the myelin oligodendrocyte glycoprotein (MOG) antibody negative patient group. Listed proteins were shown to be autoantibody target in at least two samples per group; protein reactivity of only one patient per group was not included in this list. Source: uniprot.org.

\begin{tabular}{|c|c|c|c|}
\hline Protein Symbol & Protein Name and Known Function & $\begin{array}{c}\text { MOG } \\
\text { Antibody } \\
\text { Negative }\end{array}$ & $\begin{array}{c}\text { MOG } \\
\text { Antibody } \\
\text { Positive }\end{array}$ \\
\hline MLLT6 & $\begin{array}{l}\text { Myeloid/lymphoid or mixed-lineage leukaemia, } \\
\text { translocated to, } 6\end{array}$ & 4 & 1 \\
\hline RDBP & $\begin{array}{l}\text { RNA binding protein, component of negative elongation } \\
\text { factor E (NELF-E) of transcription }\end{array}$ & 3 & 1 \\
\hline SH2D2A & $\begin{array}{l}\mathrm{SH} 2 \text { domain containing } 2 \mathrm{~A} \text {, adaptor protein thought to } \\
\text { function in } \mathrm{T} \text { cell signal transduction }\end{array}$ & 2 & 0 \\
\hline MYOT & Myotilin, stability of thin filaments during muscle contraction & 2 & 0 \\
\hline PALM2 & $\begin{array}{l}\text { Paralemmin-2, implicated in plasma membrane dynamics in } \\
\text { neurons and other cell types }\end{array}$ & 2 & 0 \\
\hline C11orf63 & $\begin{array}{l}\text { Chromosome } 11 \text { open reading frame } 63 \text {, } \\
\text { protein not characterized }\end{array}$ & 2 & 0 \\
\hline LOC283663 & $\begin{array}{l}\text { Predicted: Homo sapiens hypothetical protein LOC } 283663 \text {, } \\
\text { protein not characterized }\end{array}$ & 2 & 0 \\
\hline KCNAB1 v1/v3 & $\begin{array}{l}\text { Voltage-gated potassium channel subunit beta-1, } \\
\text { variants } 1 \text { and } 3\end{array}$ & 2 & 0 \\
\hline KEAP1 & $\begin{array}{l}\text { Kelch-like ECH-associated protein 1, regulates antioxidant } \\
\text { response and ubiquitination }\end{array}$ & 2 & 1 \\
\hline
\end{tabular}

\subsection{Rat Brain Immunohistochemistry Revealed No Potential Novel Target in Paediatric ADEM}

To enlarge the range of potential neuronal and glial surface and intracellular antigens, we also applied the sera to rat brain sections. All tested sera were negative for antibodies to neuronal surface 
and cerebellar intracellular antigens. Two out of five MOG antibody positive patients showed a positive myelin staining in rat brain sections, thereby confirming the validity of the method. The lack of reactivity in the remaining three MOG antibody positive patients can presumably be attributed to species-dependent differential binding patterns [13]. A representative staining of a MOG antibody positive sample is shown in Figure S2.

\subsection{Sera of Paediatric MOG Antibody Negative ADEM Patients Did Not Contain Antibodies against Leucine-Rich Glioma-Inactivated 1 (LGI1) and Contactin-Associated Protein-2 (CASPR2)}

Since we identified the potassium channel related proteins KCNAB1, KCNAB2, KCTD6, and KCTD18 as potential target antigens in the group of MOG antibody negative ADEM patients, we analysed all samples for antibodies against voltage gated potassium channel (VGKC) associated proteins leucine-rich glioma-inactivated 1 (LGI1) and contactin-associated protein-2 (CASPR2), which have been reported in subgroups of paediatric inflammatory neurological diseases [14,15]. However, in our cohort of paediatric ADEM patients we did not find any reactivity against the extracellular domains of these VGKC associated proteins.

\subsection{Antibodies against Recombinant Myelin Proteins/Peptides Did Not Reveal Significant Differences between the Two Groups}

Reactivity to myelin peptides was analysed using enzyme-linked immunosorbent assay (ELISA). Antibody responses against rhMOG(1-125), myelin basic protein (MBP), and synthetic myelin peptides (MOG(1-20), MOG(35-55), MBP(13-32), MBP(83-99), MBP(111-129), MBP(146-170), and proteolipid protein PLP(139-154)) were not significantly altered between patients with MOG antibodies and the seronegative group (Figure S3). As controls, we included myelin peptide antibody reactivity from 10 adult MS patients which was recently published [16].

\section{Discussion}

Autoantibodies in demyelinating and other inflammatory neurological diseases are of scientific and clinical interest, and are often associated with pathogenetic events, such as aquaporin-4 (AQP4) autoantibodies in neuromyelitis optica spectrum disorders (NMOSD) [17]. The identification of MOG antibodies as potential biological markers for ADEM motivated several research groups to search for new antibodies against myelin and non-myelin antigens in the CNS [18,19]. For this reason, we aimed to analyse paediatric MOG-negative ADEM patients for potential new autoantibodies with a high throughput method and IHC. We indeed found antibody reactivity to several candidate proteins in MOG antibody seronegative ADEM patients, but none of them was significantly different to the seropositive group. However, due to the small patient numbers, results from statistical analysis should be considered preliminary. Moreover, there may be various rare autoantibodies present only in very few patients and much larger studies would be needed to identify these.

A further limitation of our study was the lack of MOG as antigen on the protein array, although it was claimed to be included on the protein array by a previous publication of Querol et al. using the same protein array [20]. Therefore, MOG antibodies from our seropositive cohort could not be used as a positive control. Likewise, many other neuronal and glial antigens-such as CASPR2 or AQP4-are not present in the protein microarray. Another limitation could be a lack of sensitivity of the assay, due to high background values. However, this was excluded by compensatory statistics. Nevertheless, sensitivity of this microarray was confirmed by the detection of cyclic citrullinated peptide (CCP) antibodies, an established biomarker for rheumatoid arthritis in one patient. Since this patient did not (yet) show any clinical symptoms related to rheumatoid arthritis, and since CCP antibody levels of this patient were below the diagnostic cut-off in a validated ELISA (data not shown), it is likely that the cut-off z-score (2.33) used here might be below the clinically relevant threshold.

The spotting of native proteins in a microarray format does not preserve all original conformational epitopes, which could yield false-negative results, and therefore missing antibodies to 
conformational epitopes. The importance of an intact conformation to detect disease-related antibodies has been evidenced previously, when MOG antibodies were falsely identified as a prognostic biomarker for MS, but were observed also in several healthy control samples, using recombinant or denatured protein [21,22]. In our study, we also detected antibody responses to MOG, MBP, and PLP peptides in both MOG antibody negative and positive ADEM groups with no significant differences. A previous microarray study [18] analysing antibody reactivity to myelin peptides in patients with ADEM and paediatric/adult MS demonstrated distinct profiles of myelin antibody reactivity in these two groups, specifically autoantibodies of the immunoglobulin G (IgG) isotype to MBP and myelin-associated oligodendrocyte basic protein (MOBP) in ADEM patients. However, in our study we could not confirm these results when comparing ADEM and adult MS patients.

The finding of two MOG antibody negative patients with reactivity to KCNAB1 and KCNAB2, members of the VGKC-superfamily, and also members of the potassium channel tetramerisation domain (KCTD18, KCTD6), prompted us to test for antibodies against VGKC associated proteins LGI1 and CASPR2, due to a reported association with inflammatory neurologic diseases in children [14,15]. However, testing against VGKC associated proteins LGI1 and CASPR2 did not reveal any positive results. These findings are in line with a previous study [23] in which only a subset of VGKC antibodies also bound LGI1 and CASPR2, whereas the other antibodies targeted intracellular epitopes and non-neuronal targets.

Additional proteins listed in Table 1 are of intracellular origin (Source: Uniprot), of unknown function or not directly associated with the CNS, and therefore not of interest as relevant targets in this study. Furthermore, it is very likely that these antibodies to intracellular proteins are part of the normal immune repertoire (natural autoantibodies) and only a side effect of cellular degradation processes.

Although we aimed to increase the number of possible intracellular and surface neuronal and glial antigens by using IHC for antibody screening, we could not detect possible antibodies to conformational epitopes with this method, which is commonly used to detect antibodies to intracellular and surface neuronal targets. One potential cause could be the species-specific alteration of amino acid sequences within the recognized antigen epitopes [13]. This is also underlined by the fact that only 2/5 MOG antibody positive patients showed a specific myelin staining on rat tissue.

The use of cerebrospinal fluid (CSF) for screening could have yielded further novel candidate autoantigens, and CSF antibody testing is highly recommended for antibody-mediated neurological autoimmune diseases such as autoimmune encephalitis [24]. On the other hand, MOG antibodies are only rarely found in CSF of ADEM patients, suggesting that there is no intrathecal synthesis of the antibodies [25]. It therefore remains speculative if CSF is superior for antibody screening in the patients investigated here.

\section{Materials and Methods}

\subsection{Patients and Samples}

Patients' serum samples were collected in the Clinical Department of Neurology Innsbruck between 2009 and 2013 and stored at $-80{ }^{\circ} \mathrm{C}$ until use. All patients were diagnosed with a definite monophasic ADEM. The diagnosis was based on the diagnostic criteria of the IPMSSG with clinical assessments according to clinical CNS events, with a probable inflammatory demyelinating cause, and encephalopathy not related to fever, systemic illness, or postictal symptoms [1]. Abnormal cerebral and spinal cord lesions, not indicative of other CNS diseases, were diagnosed by magnetic resonance imaging (MRI). Laboratory tests included cell counts and Ig levels in the CSF. All serum samples analysed in this study were drawn at the acute demyelinating event before immunosuppressive therapy was initiated (baseline). In five of 16 patients, antibodies against MOG were found at baseline [12], with decreasing titres after the first follow up (median age: 4.7 years (range: 2.98-7.01), f:m = 2:3). Seronegative patients (median age 6.2 years (range: 1.13-13.51), f:m $=4: 7$ ) had no symptomatic differences compared to MOG antibody seropositive patients. This study was approved by the Ethical 
Committee of the Medical University of Innsbruck (study number AM4059). All parents and patients (older than 12 years) gave written informed consent to the study protocol.

\subsection{Protein Microarray}

Before use, all serum samples were thawed at room temperature (RT) and centrifuged at $3000 \times g$ for $10 \mathrm{~min}$ at $4{ }^{\circ} \mathrm{C}$.

In total, 16 serum samples (11 MOG antibody negative, 5 MOG antibody positive) were used for the ProtoArray ${ }^{\circledR}$ Human Protein Microarray v5.0 (Invitrogen, Carlsbad, CA, USA). These microarrays contain duplicates of 9375 human full-length native proteins, expressed as N-terminal glutathione $S$-transferase (GST) fusion proteins using a baculovirus-based expression system. ProtoArrays ${ }^{\circledR}$ were handled according to the manufacturer's guidelines and recommendations. Briefly, slides were equilibrated at $4{ }^{\circ} \mathrm{C}$ and left on ice for the whole procedure. All buffers, reagents, and samples were cooled down to $4{ }^{\circ} \mathrm{C}$ before usage and handled under sterile conditions. Slides were incubated with Blocking Buffer (50 mM HEPES (Sigma-Aldrich, Saint Louis, MO, USA), pH 7.5, 200 mM $\mathrm{NaCl}$ (Merck, Darmstadt, Germany), 0.08\% Triton ${ }^{\circledR}$ X-100 (Merck), 25\% Glycerol (Sigma-Aldrich), $20 \mathrm{mM}$ reduced glutathione (Sigma-Aldrich), $1 \times$ Synthetic Block (Sigma-Aldrich), $1 \mathrm{mM}$ Dithiothreitol (Sigma-Aldrich)) for $1 \mathrm{~h}$ with gentle agitation. After aspiration of Blocking Buffer, $5 \mathrm{~mL}$ of diluted serum (1:500 in Washing Buffer (1× phosphate buffer saline (PBS), 0.1\% Tween 20, $1 \times$ Synthetic Block (all Sigma-Aldrich)) were added to each slide and incubated for $90 \mathrm{~min}$ with gentle agitation. Arrays were then washed five times with Washing Buffer for $5 \mathrm{~min}$. Human bound antibodies were labelled with Alexa Fluor ${ }^{\circledR} 647$ goat anti human IgG antibody (Life Technologies, Carlsbad, CA, USA) 1:2000 in Washing Buffer for 90 min with gentle shaking, followed by five washing steps. Finally, arrays were rinsed with deionized water and centrifuged at $200 \times g$ for $1 \mathrm{~min}$. ProtoArrays ${ }^{\circledR}$ were scanned with a GenePix 4000B array scanner (Axon Instruments Inc., Union City, CA, USA) at a wavelength of $635 \mathrm{~nm}$. Images were analysed and the array grid was acquired with the Prospector Imager v5.2.3 software (Invitrogen).

\subsection{Rat Brain Immunohistochemistry}

All serum samples were analysed for IgG antibodies directed either to surface (neuropil staining) or intracellular antigens by IHC on snapfrozen rat brain tissue as described previously, methods that are optimized to detect surface or intracellular unknown antibody targets [26]. In brief, rats were sacrificed with $\mathrm{CO}_{2}$ and underwent two different protocols for antigen staining. For the surface staining, native brain was dissected, sagittally sectioned, and fixed with $4 \%$ PFA (paraformaldehyde) (Affymetrix, Santa Clara, CA, USA) in $1 \times$ PBS (Morphisto, Frankfurt am Main., Germany) for $1 \mathrm{~h}$ at $4{ }^{\circ} \mathrm{C}$. Brain hemispheres were then cryoprotected with $40 \%$ sucrose (Merck) for $48 \mathrm{~h}$ at $4{ }^{\circ} \mathrm{C}$, subsequently embedded in freezing medium (O.C.T. ${ }^{\mathrm{TM}}$, Tissue-Tek ${ }^{\circledR}$, Sakura, Alphen aan den Rijn, The Netherlands), and quickly frozen with liquid nitrogen pre-chilled methylbutan (Sigma-Aldrich).

Frozen sections $(7 \mu \mathrm{m})$ were stored at $-20{ }^{\circ} \mathrm{C}$ until use, and then thawed at RT for $20 \mathrm{~min}$, washed once with PBS, and incubated with $0.3 \%$ hydrogen peroxide for $15 \mathrm{~min}$. After washing three times with PBS, slides were incubated in a humidity chamber with $5 \%$ donkey serum (Millipore, Billerica, MA, USA) in PBS for $1.5 \mathrm{~h}$ at RT. After removal of the blocking solution, slides were incubated with diluted serum samples (1:200 in 5\% donkey serum) overnight at $4{ }^{\circ} \mathrm{C}$. The day after, slides were washed three times and incubated with a biotinylated donkey anti-human IgG secondary antibody (Jackson Immuno Research, West Grove, PA, USA) (1:2000, diluted in 5\% donkey serum) for $2 \mathrm{~h}$ at RT and washed again three times with PBS. An avidin/biotinylated enzyme complex (Vector laboratories, Burlingame, CA, USA) was added for $1 \mathrm{~h}$ and subsequently washed three times. Slides were placed in 1:200 diluted Triton X-100 for $30 \mathrm{~s}$ and staining was developed with diaminobenzidine (Dako, Glostrup, Denmark) for $7 \mathrm{~min}$. For surface antigen staining, a serum sample positive for $\alpha$-amino-3-hydroxy-5-methyl-4-isoxazolepropionic acid receptor (AMPAR) antibodies was used as positive control. 
For intracellular antigen screening, rats were perfused with 2\% PFA, subsequently decapitated, and the brain dissected. Tissue was fixed in $2 \%$ PFA for $4 \mathrm{~h}$ at $4{ }^{\circ} \mathrm{C}$ and cryoprotected in $20 \%$ sucrose for 2-3 days at $4{ }^{\circ} \mathrm{C}$. Isolated cerebellum was embedded in freezing medium and prepared for staining, as explained previously. Each tissue section was incubated for $30 \mathrm{~min}$ with blocking solution $(10 \%$ donkey serum in PBS with $0.1 \%$ Triton X-100) and then labelled with diluted sera (1:500 in blocking solution) for $3 \mathrm{~h}$ at $37^{\circ} \mathrm{C}$ in a humidity chamber. Afterwards, slides were washed twice with PBS and incubated with biotinylated donkey anti-human IgG (1:4000 in PBS) for $30 \mathrm{~min}$ at RT. Thereafter, slides were washed twice with PBS and subsequently incubated with an avidin/biotinylated enzyme complex for $30 \mathrm{~min}$. Slides were washed twice and the enzyme reaction was completed with diaminobenzidine for $5 \mathrm{~min}$. For intracellular antigen staining, serum samples positive for either glutamic acid decarboxylase (GAD) or SOX antibodies were used as positive controls.

\subsection{Immunocytochemistry}

Samples that showed increased reactivity to potassium channel proteins in the protein microarray were tested on commercially available indirect immunofluorescence tests for antibodies against VGKC associated proteins LGI1 and CASPR2 (Euroimmun, Lübeck, Germany). The test was used according to the manual. In brief, LGI1 and CASPR2 transfected HEK293 cells fixed on BIOCHIP slides were incubated with 1:10 diluted serum samples for $30 \mathrm{~min}$ at RT and subsequently washed with $0.2 \%$ PBS-Tween for $5 \mathrm{~min}$. Serum antibodies were labelled with a fluorescein isothiocyanate (FITC) conjugated anti-human IgG antibody for 30 min under protection of light and washed with $0.2 \%$ PBS-Tween for another $5 \mathrm{~min}$. Slides were analysed with a fluorescence microscope (Leica DMI 4000B, Wetzlar, Germany) by at least two investigators (Patrick Peschl, Melanie Ramberger, Markus Reindl).

\subsection{Enzyme-Linked Immunosorbent Assay (ELISA) to Myelin Antigens}

Serum IgG antibodies to the recombinant human MOG extracellular Ig domain (rhMOG, amino acids 1-125), produced in Escherichia coli bacteria [27], human myelin basic protein (MBP) purified from human brain [28], and synthetic peptides MOG(1-20), MOG(35-55), MBP(13-32), MBP(83-99), MBP(111-129), MBP(146-170), and proteolipid protein [PLP(139-154)] were analysed by ELISA, as described previously $[16,29,30]$.

\subsection{Statistical Analyses}

Microarrays were analysed with the Invitrogen ProtoArray ${ }^{\circledR}$ Prospector Software v5.2.3 (Invitrogen). This software first applies a quantile normalization which is based on the Chebyshev's inequality principle (CI-P). Therein, an algorithm compares the signal from each protein on the microarray with the signals from the negative control features, to assign a CI-P value. Each signal is then compared to the mean value and the standard deviation of all the signals coming from all proteins spotted on the array resulting in a z-score, indicating the signal strength of each protein. Median values of each $z$-score duplicate were assessed and a quantile of all signal intensities was evaluated. Only protein signals with z-scores above the $1 \%$ top quantile of 2.33 were considered significant hits. Between-group comparisons were performed using matched two-way ANOVA. Statistical analysis and drawing of figures was performed using GraphPad PRISM 7 (GraphPad Software Inc., La Jolla, CA, USA).

\section{Conclusions}

In conclusion, we found antibody reactivity to several candidate proteins in MOG antibody seronegative ADEM patients, but the methods used here comprise several limitations. Bearing in mind the importance of novel biomarkers for therapeutic and prognostic purposes, other methods for antibody screening should be used in future studies. In particular, the preservation of original conformational epitopes should be considered. 
Supplementary Materials: Supplementary materials can be found at www.mdpi.com/1422-0067/18/3/679/s1.

Acknowledgments: This study was supported by a research grant from the Fonds zur Förderung der wissenschaftlichen Forschung, Austria (FWF graduate program W1206 SPIN to Patrick Peschl, Melanie Ramberger and Markus Reindl) and a research grant from the Österreichische Nationalbank [OeNB (grant Jubiläumsfondsprojekt Nr. 15918) to Kevin Rostásy]. The open access publishing costs were funded by the FWF (project W1206 SPIN). The authors wish to thank Nora Löwy, Valierie Pichler and Kathrin Schanda for excellent technical assistance.

Author Contributions: Patrick Peschl, Melanie Ramberger, Romana Höftberger, and Markus Reindl conceived and designed experiments; Patrick Peschl, Melanie Ramberger, and Romana Höftberger performed the experiments; Patrick Peschl, Melanie Ramberger, Romana Höftberger, and Markus Reindl analysed the data; Romana Höftberger, Karin Jöhrer, Matthias Baumann, and Kevin Rostásy contributed reagents/materials/analysis tools; Patrick Peschl, Melanie Ramberger, and Markus Reindl wrote the paper; all authors read and approved the final version of the manuscript.

Conflicts of Interest: The Medical University of Innsbruck and University Hospital Innsbruck and Medical University of Vienna receive payments for antibody assays (aquaporin-4 and other anti-neuronal and anti-glial antibodies) and for aquaporin-4 antibody validation assays organized by Euroimmun (Lübeck, Germany). The funding sponsors had no role in the design of the study; in the collection, analyses, or interpretation of data; in the writing of the manuscript, and in the decision to publish the results.

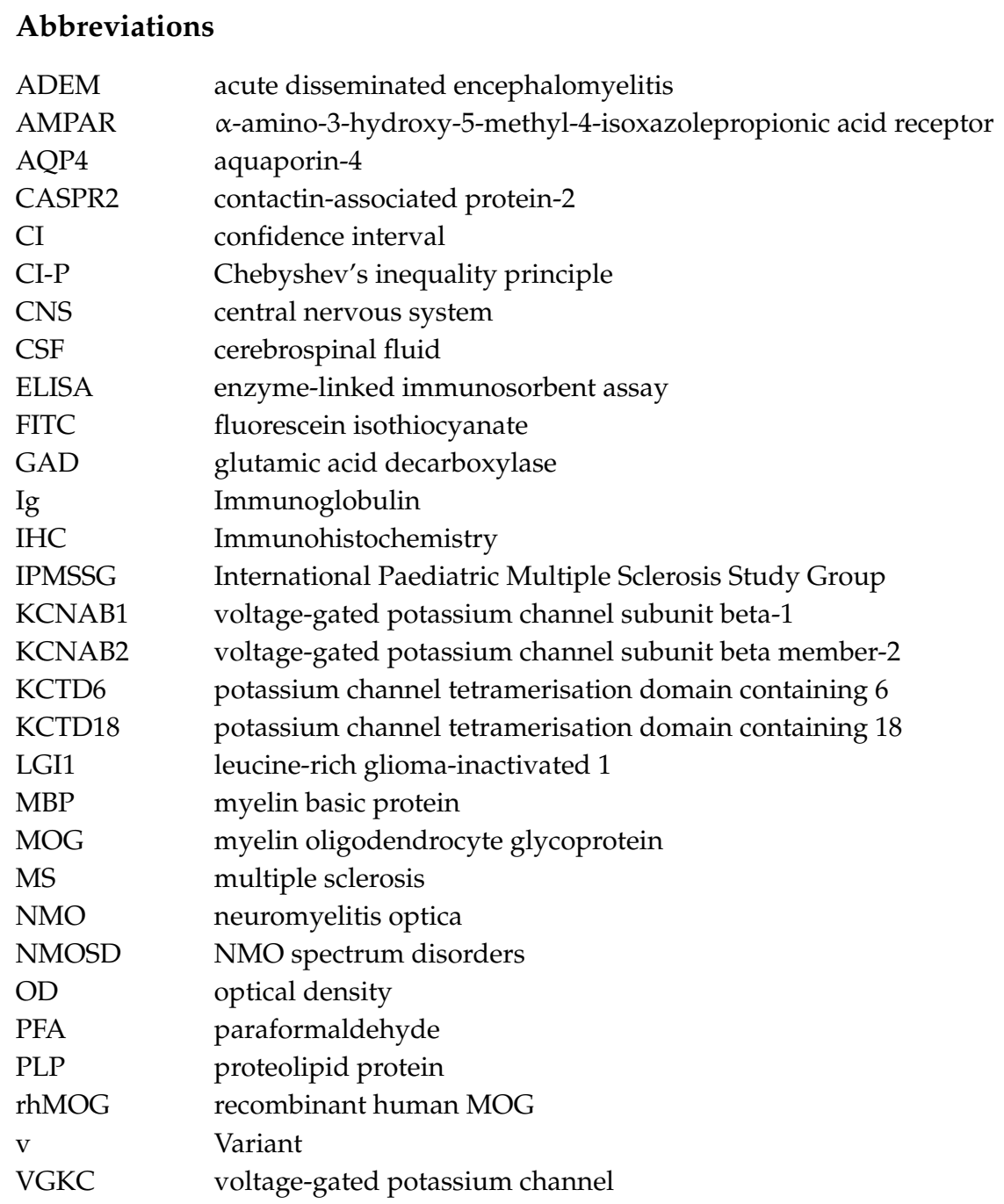

\section{References}

1. Krupp, L.B.; Tardieu, M.; Amato, M.P.; Banwell, B.; Chitnis, T.; Dale, R.C.; Ghezzi, A.; Hintzen, R.; Kornberg, A.; Pohl, D.; et al. International pediatric multiple sclerosis study group criteria for pediatric multiple sclerosis and immune-mediated central nervous system demyelinating disorders: Revisions to the 2007 definitions. Mult. Scler. 2013, 19, 1261-1267. [CrossRef] [PubMed] 
2. Tenembaum, S.N. Acute disseminated encephalomyelitis. Handb. Clin. Neurol. 2013, 112, $1253-1262$. [PubMed]

3. Brilot, F.; Dale, R.C.; Selter, R.C.; Grummel, V.; Kalluri, S.R.; Aslam, M.; Busch, V.; Zhou, D.; Cepok, S.; Hemmer, B. Antibodies to native myelin oligodendrocyte glycoprotein in children with inflammatory demyelinating central nervous system disease. Ann. Neurol. 2009, 66, 833-842. [CrossRef] [PubMed]

4. O'Connor, K.C.; McLaughlin, K.A.; De Jager, P.L.; Chitnis, T.; Bettelli, E.; Xu, C.; Robinson, W.H.; Cherry, S.V.; Bar-Or, A.; Banwell, B.; et al. Self-antigen tetramers discriminate between myelin autoantibodies to native or denatured protein. Nat. Med. 2007, 13, 211-217. [CrossRef] [PubMed]

5. McLaughlin, K.A.; Chitnis, T.; Newcombe, J.; Franz, B.; Kennedy, J.; McArdel, S.; Kuhle, J.; Kappos, L.; Rostasy, K.; Pohl, D.; et al. Age-dependent B cell autoimmunity to a myelin surface antigen in pediatric multiple sclerosis. J. Immunol. 2009, 183, 4067-4076. [CrossRef] [PubMed]

6. Probstel, A.K.; Dornmair, K.; Bittner, R.; Sperl, P.; Jenne, D.; Magalhaes, S.; Villalobos, A.; Breithaupt, C.; Weissert, R.; Jacob, U.; et al. Antibodies to MOG are transient in childhood acute disseminated encephalomyelitis. Neurology 2011, 77, 580-588. [CrossRef] [PubMed]

7. Di Pauli, F.; Mader, S.; Rostasy, K.; Schanda, K.; Bajer-Kornek, B.; Ehling, R.; Deisenhammer, F.; Reindl, M.; Berger, T. Temporal dynamics of anti-MOG antibodies in cns demyelinating diseases. Clin. Immunol. 2011, 138, 247-254. [CrossRef] [PubMed]

8. Hacohen, Y.; Absoud, M.; Deiva, K.; Hemingway, C.; Nytrova, P.; Woodhall, M.; Palace, J.; Wassmer, E.; Tardieu, M.; Vincent, A.; et al. Myelin oligodendrocyte glycoprotein antibodies are associated with a non-MS course in children. Neurol. Neuroimmunol. Neuroinflamm. 2015, 2, e81. [CrossRef] [PubMed]

9. Dale, R.C.; Tantsis, E.M.; Merheb, V.; Kumaran, R.Y.; Sinmaz, N.; Pathmanandavel, K.; Ramanathan, S.; Booth, D.R.; Wienholt, L.A.; Prelog, K.; et al. Antibodies to MOG have a demyelination phenotype and affect oligodendrocyte cytoskeleton. Neurol. Neuroimmunol. Neuroinflamm. 2014, 1, e12. [CrossRef] [PubMed]

10. Ketelslegers, I.A.; Van Pelt, D.E.; Bryde, S.; Neuteboom, R.F.; Catsman-Berrevoets, C.E.; Hamann, D.; Hintzen, R.Q. Anti-MOG antibodies plead against ms diagnosis in an acquired demyelinating syndromes cohort. Mult. Scler. 2015, 21, 1513-1520. [CrossRef] [PubMed]

11. Fernandez-Carbonell, C.; Vargas-Lowy, D.; Musallam, A.; Healy, B.; McLaughlin, K.; Wucherpfennig, K.W.; Chitnis, T. Clinical and MRI phenotype of children with MOG antibodies. Mult. Scler. 2016, 22, 174-184. [CrossRef] [PubMed]

12. Baumann, M.; Sahin, K.; Lechner, C.; Hennes, E.M.; Schanda, K.; Mader, S.; Karenfort, M.; Selch, C.; Hausler, M.; Eisenkolbl, A.; et al. Clinical and neuroradiological differences of paediatric acute disseminating encephalomyelitis with and without antibodies to the myelin oligodendrocyte glycoprotein. J. Neurol. Neurosurg. Psychiatry 2015, 86, 265-272. [CrossRef] [PubMed]

13. Mayer, M.C.; Breithaupt, C.; Reindl, M.; Schanda, K.; Rostasy, K.; Berger, T.; Dale, R.C.; Brilot, F.; Olsson, T.; Jenne, D.; et al. Distinction and temporal stability of conformational epitopes on myelin oligodendrocyte glycoprotein recognized by patients with different inflammatory central nervous system diseases. J. Immunol. 2013, 191, 3594-3604. [CrossRef] [PubMed]

14. Hacohen, Y.; Singh, R.; Rossi, M.; Lang, B.; Hemingway, C.; Lim, M.; Vincent, A. Clinical relevance of voltage-gated potassium channel-complex antibodies in children. Neurology 2015, 85, 967-975. [CrossRef] [PubMed]

15. Hacohen, Y.; Nishimoto, Y.; Fukami, Y.; Lang, B.; Waters, P.; Lim, M.J.; Yuki, N.; Vincent, A. Paediatric brainstem encephalitis associated with glial and neuronal autoantibodies. Dev. Med. Child Neurol. 2016, 58, 836-841. [CrossRef] [PubMed]

16. Peschl, P.; Reindl, M.; Schanda, K.; Sospedra, M.; Martin, R.; Lutterotti, A. Antibody responses following induction of antigen-specific tolerance with antigen-coupled cells. Mult. Scler. 2014, 21, 651-655. [CrossRef] [PubMed]

17. Wingerchuk, D.M.; Banwell, B.; Bennett, J.L.; Cabre, P.; Carroll, W.; Chitnis, T.; de Seze, J.; Fujihara, K.; Greenberg, B.; Jacob, A.; et al. International consensus diagnostic criteria for neuromyelitis optica spectrum disorders. Neurology 2015, 85, 177-189. [CrossRef] [PubMed]

18. Van Haren, K.; Tomooka, B.H.; Kidd, B.A.; Banwell, B.; Bar-Or, A.; Chitnis, T.; Tenembaum, S.N.; Pohl, D.; Rostasy, K.; Dale, R.C.; et al. Serum autoantibodies to myelin peptides distinguish acute disseminated encephalomyelitis from relapsing-remitting multiple sclerosis. Mult. Scler. 2013, 19, 1726-1733. [CrossRef] [PubMed] 
19. Kaliakatsos, M.; Hacohen, Y.; Siddiqui, A.; Dlamini, N.; Vincent, A.; Lim, M. Acute disseminated encephalomyelitis associated with positive voltage gated potassium channel complex antibody. Mult. Scler. Relat. Disord. 2013, 2, 147-150. [CrossRef] [PubMed]

20. Querol, L.; Clark, P.L.; Bailey, M.A.; Cotsapas, C.; Cross, A.H.; Hafler, D.A.; Kleinstein, S.H.; Lee, J.Y.; Yaari, G.; Willis, S.N.; et al. Protein array-based profiling of CSF identifies RBPJ as an autoantigen in multiple sclerosis. Neurology 2013, 81, 956-963. [CrossRef] [PubMed]

21. Berger, T.; Rubner, P.; Schautzer, F.; Egg, R.; Ulmer, H.; Mayringer, I.; Dilitz, E.; Deisenhammer, F.; Reindl, M. Antimyelin antibodies as a predictor of clinically definite multiple sclerosis after a first demyelinating event. N. Engl. J. Med. 2003, 349, 139-145. [CrossRef] [PubMed]

22. Kuhle, J.; Pohl, C.; Mehling, M.; Edan, G.; Freedman, M.S.; Hartung, H.P.; Polman, C.H.; Miller, D.H.; Montalban, X.; Barkhof, F.; et al. Lack of association between antimyelin antibodies and progression to multiple sclerosis. N. Engl. J. Med. 2007, 356, 371-378. [CrossRef] [PubMed]

23. Lang, B.; Makuch, M.; Moloney, T.; Dettmann, I.; Mindorf, S.; Probst, C.; Stoecker, W.; Buckley, C.; Newton, C.R.; Leite, M.I.; et al. Intracellular and non-neuronal targets of voltage-gated potassium channel complex antibodies. J. Neurol. Neurosurg. Psychiatry 2017. [CrossRef] [PubMed]

24. Graus, F.; Titulaer, M.J.; Balu, R.; Benseler, S.; Bien, C.G.; Cellucci, T.; Cortese, I.; Dale, R.C.; Gelfand, J.M.; Geschwind, M.; et al. A clinical approach to diagnosis of autoimmune encephalitis. Lancet Neurol. 2016, 15, 391-404. [CrossRef]

25. Jarius, S.; Ruprecht, K.; Kleiter, I.; Borisow, N.; Asgari, N.; Pitarokoili, K.; Pache, F.; Stich, O.; Beume, L.A.; Hummert, M.W.; et al. MOG-IgG in NMO and related disorders: A multicenter study of 50 patients. Part 1: Frequency, syndrome specificity, influence of disease activity, long-term course, association with AQP4-IgG, and origin. J. Neuroinflamm. 2016, 13, 279. [CrossRef] [PubMed]

26. Hoftberger, R.; Sabater, L.; Marignier, R.; Aboul-Enein, F.; Bernard-Valnet, R.; Rauschka, H.; Ruiz, A.; Blanco, Y.; Graus, F.; Dalmau, J.; et al. An optimized immunohistochemistry technique improves NMO-IgG detection: Study comparison with cell-based assays. PLoS ONE 2013, 8, e79083. [CrossRef] [PubMed]

27. Reindl, M.; Linington, C.; Brehm, U.; Egg, R.; Dilitz, E.; Deisenhammer, F.; Poewe, W.; Berger, T. Antibodies against the myelin oligodendrocyte glycoprotein and the myelin basic protein in multiple sclerosis and other neurological diseases: A comparative study. Brain J. Neurol. 1999, 122 Pt 11, 2047-2056. [CrossRef]

28. Rauer, S.; Euler, B.; Reindl, M.; Berger, T. Antimyelin antibodies and the risk of relapse in patients with a primary demyelinating event. J. Neurol. Neurosurg. Psychiatry 2006, 77, 739-742. [CrossRef] [PubMed]

29. Khalil, M.; Reindl, M.; Lutterotti, A.; Kuenz, B.; Ehling, R.; Gneiss, C.; Lackner, P.; Deisenhammer, F.; Berger, T. Epitope specificity of serum antibodies directed against the extracellular domain of myelin oligodendrocyte glycoprotein: Influence of relapses and immunomodulatory treatments. J. Neuroimmunol. 2006, 174, 147-156. [CrossRef] [PubMed]

30. Pittock, S.J.; Reindl, M.; Achenbach, S.; Berger, T.; Bruck, W.; Konig, F.; Morales, Y.; Lassmann, H.; Bryant, S.; Moore, S.B.; et al. Myelin oligodendrocyte glycoprotein antibodies in pathologically proven multiple sclerosis: Frequency, stability and clinicopathologic correlations. Mult. Scler. 2007, 13, 7-16. [CrossRef] [PubMed]

(C) 2017 by the authors. Licensee MDPI, Basel, Switzerland. This article is an open access article distributed under the terms and conditions of the Creative Commons Attribution (CC BY) license (http://creativecommons.org/licenses/by/4.0/). 